4. The variation of temperature (below $100^{\circ}$ ) and concentration does not alter the nature of the reaction.

Corvalis, Oregon.

[From the Phystological, laboratory, Coriel, Univeristy Medical College NEW YORK CITY.]

\title{
AN IMPROVED TYPE OF CALORIMETER, TO BE USED WITH ANY CALORIMETRIC BOMB.
}

By J. A. RIChE.

Received July 3, 1913.

The calorimeters in general use are subject to many errors, namely those of radiation through the surrounding wall, of conduction through the metallic parts and the thermometer, and those due to the inaccuracy of the thermometer readings. Richards ${ }^{1}$ has shown that there may be considerable error due to a lack of quick response in the thermometer (the thermometer lag).

The present paper deals with an attempt to eliminate all these errors, through the use of a vacuum cup with a suitable covering, proper precaution having been taken to insulate the different parts.

The vacuum cup has been used by Rubner ${ }^{2}$ to show the heat formed by active bacteria, and also recently by $\mathrm{Hill}^{3}$ for a calorimeter with which he attempted to measure the heat produced in rats. ${ }^{4}$

Benedict ${ }^{5}$ has constructed an adiabatic calorimeter for use with the bomb, which has many advantages over the older styles of calorimeters but it requires a special technique.

Description of Apparatus. - In all calorimetric work the rise in temperature, multiplied by the quantity of water affected, gives the calories directly, provided there is no loss or gain in heat. Figure I is a sectional sketch of the bomb and calorimeter, which has been designed. It consists of a bomb, $a$, which may be of any type, of a vacuum cup, $b$, containing water, a stirrer, $j$, and a thermometer, $T$. The stirrer is of the screw propeller type, which is far more efficient than any other. ${ }^{6}$ The vacuum cup is of standard size, $14 \mathrm{~cm}$. wide, $30 \mathrm{~cm}$. high, inside measurements, and was obtained through the Vereinigte Fabriken $f$. Laboratoriumsbedarf, Berlin, Germany.

The bomb is of the Kroecker style and, inasmuch as it has two outlets, 4-5, a determination of carbon may be made. The support for the bomb

${ }_{1}^{1}$ Richards, Henderson and Freuert, Proc. Amer. Acad. Arts and Science, 4r, (Ig05).

${ }^{2}$ Arch. Hyg., 48, 260-68.

${ }^{3} J$. Physiol., 46, (1913).

4 Curiously enough, Hill in his computations neglects to take into account the heat lost through the vaporization of water by the animals employed.

- This Journal, 32 (1910).

- U. S. Bureau of Standards, Circular No. II, Ist ed., May, I9I I. 


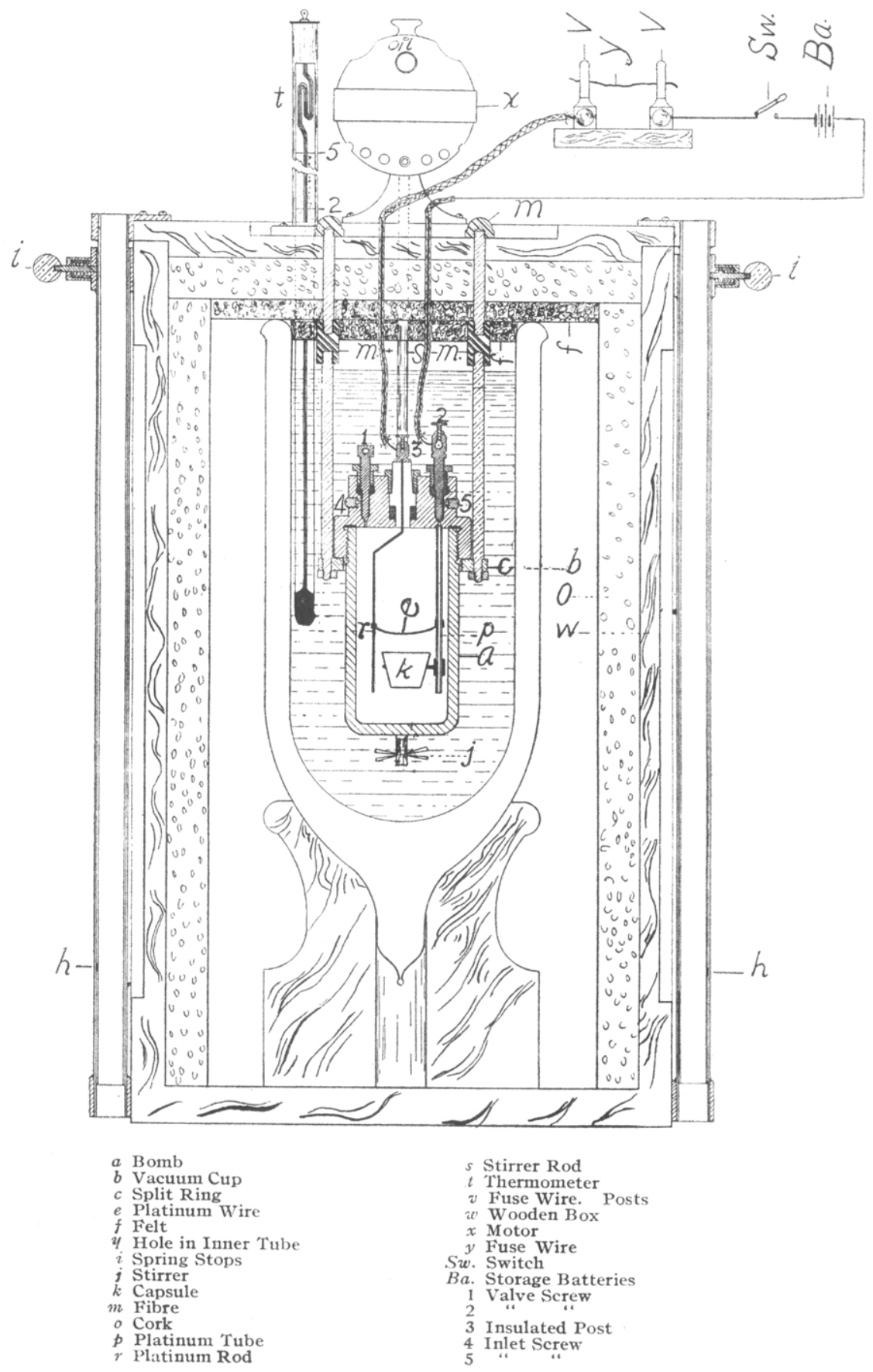


is a hinged ring, $c$, supported by two brass rods connected with the cover. The rods are insulated by passing them through hard rubber, $m$, and a hard rubber cap is screwed on the end of each rod (see sketch).

To prevent any possible heat loss from the vacuum cup, it is surrounded by an oak box, $w$, lined with one inch pressed cork, $o$, which is glued to the wood. On the cover, in addition to the cork, is glued a piece of hair felt, $f$, one-half inch in thickness, effecting a tight joint with the top of the vacuum cup.

A hinged door in the front facilitates the handling of the vacuum cup and the cover is raised and lowered by means of telescope tubes, thus giving opportunity to place the bomb in the split ring and to adjust the ignition wires. After the cover is lowered, the thermometer is placed in position through a hole in the cover, into which is screwed a brass tube to support and protect it.

Method of Making a Combustion.-The substance to be burned is prepared, weighed and placed in the bomb, which, after being charged with 30 to 40 atmospheres of oxygen, is then placed in the split ring and the wires connected. The water in the vacuum cup is brought to any temperature within plus or minus $5.0^{\circ}$ of the room temperature, the cup is then placed in position, the door closed and the top lowered. The thermometer is adjusted and the motor started. Readings are then taken until the temperature of the water becomes constant. The sample is then ignited, by closing a switch, and readings are taken. The heat absorption is complete, when the thermometer shows a constant temperature for three successive minutes.

Temperature equilibrium having been established, the bomb is removed, opened and rinsed with water; and the rinsings are titrated with $N /$ ro alkali for nitric acid, using litmus as an indicator.

Method of Ignition.-Ignition of the substance in the bomb is accomplishd by a current from three two-volt storage cells, which first passes through a 3 ampere fuse wire, in series with a platinum wire ${ }^{1}$ within the bomb itself. The platinum wire is connected with the substance to be burned by means of a linen thread of sufficient size to secure ignition. The fuse assures the constancy of the heat of ignition.

Calculation of Results.-The reading at ignition is taken as the initial reading. This subtracted from the final reading, gives the total rise. This rise multiplied by the weight of water (plus the hydrothermal equivalent of the apparatus) gives the total number of calories liberated. From this is taken the heat resulting from the ignition, and the nitric acid formed. This result, divided by the weight of substance, gives the calories for the unit of material oxidized.

The water equivalent was determined by burning a standard sample

${ }^{1}$ No. 24 B. S. guage. 
of cane sugar, which was officially stated by the United States Bureau of Standards to have a heat value of 3,945 calories per gram, plus or minus three calories.

The amount of water used was such, that its weight, plus the hydrothermal equivalent, was the equivalent of 3,000 grams of water.

Specimen of Combustion:

Substance, cane sugar. Bureau of Standards $=3.945 \pm 3$ calories.

Weight of substance taken I.1466 grams.

Weight of water in cup............. 2,530 grams

Hydrothermal equivalent ........... 470

Water equivalent of apparatus........ 3,000 grams

\begin{tabular}{lc}
\multicolumn{2}{c}{ Before firing. } \\
Tinc. & Reading. \\
3.00 & $I .500$ \\
3.01 & I 500 \\
3.02 & $I .500$
\end{tabular}

\begin{tabular}{cc}
\multicolumn{2}{c}{ After firing. } \\
Time & Reading. \\
3.06 & 3.025 \\
3.07 & 3.030 \\
3.08 & 3.030 \\
3.09 & 3.030
\end{tabular}

Temperature of water at start $26^{\circ}$.

Temperature of room $28.5^{\circ}$.

Ignition heat. . . . . . . . . . . 60 calories

Nitric acid. . . . . . . . . . . . 4.6 calories

$3.030-1.500=1.530$ total rise.

64.6 calories

$1.530 \times 3,000=4590$ calories.

$4590-64.6=4525.4$ calories.

4525.4 divided by $1.1466=3947$ calories.

These results demonstrate the value of the use of the vacuum cup and of the method of ignition for bomb calorimeter work. It has the further recommendation of being less expensive than other bomb calorimeters of equal accuracy.

[CONTRIBUTIONS FROM THE ChEMTCAI IABORATORY OF COLUMBIA UNIVERSTTY, No. 218 .]

THE WEIGHT OF A FALLING DROP AND THE LAWS OF TATE. XIII. THE DROP WEIGHTS OF AQUEOUS SOLUTIONS AND THE SURFACE TENSIONS CALCULATED

\section{FROM THEM.}

By J. Iivingston R. Morgan and Ggorge A. BOLe.

Received August 1, 1913.

The object of this investigation ${ }^{2}$ was, first, to apply the Morgan drop-

For other papers in this series see This Journal, 30, 360-76, 1055-68; 33, 349$62,643-57,657-72,672-84,1042-60$, $1060-71,1275-90,1713-27 ; 35,1249-62,1505-24$.

2 The experimental work in connection with this paper was carried out during the winters of $I 910^{-I}$, and $191 \mathrm{I}^{-12}$ 